\title{
Modeling of Minimum and Maximum Void Ratios of Granular Soils
}

\author{
Xiaoxu Qian, ${ }^{1,2,3}$ Xin Liu $\mathbb{D}^{1,2}$ Zhiwei Shao, ${ }^{1,2}$ Yunqiang Shi, ${ }^{1,2}$ Siqing Zhang, ${ }^{1,2}$ \\ and Baoning Hong ${ }^{1,2}$ \\ ${ }^{1}$ Key Laboratory of Ministry of Education for Geomechanics and Embankment Engineering, Nanjing 210024, China \\ ${ }^{2}$ Institute of Tunnel and Underground Engineering, Hohai University, Nanjing 210024, China \\ ${ }^{3}$ School of Urban and Civil Engineering Sciences, Nanjing University Jinling College, Nanjing 210089, China
}

Correspondence should be addressed to Xin Liu; liuxin100@hhu.edu.cn

Received 17 July 2020; Revised 2 February 2021; Accepted 7 February 2021; Published 20 February 2021

Academic Editor: Ali Ramazani

Copyright (c) 2021 Xiaoxu Qian et al. This is an open access article distributed under the Creative Commons Attribution License, which permits unrestricted use, distribution, and reproduction in any medium, provided the original work is properly cited.

Determining the maximum and minimum void ratios of granular soils is very important because it can be correlated with engineering behaviors such as soil permeability. Empirical relationships can be used for determining the void ratio, but they have many limitations related to the shape and the size distribution of the grains. Analytical methods improve the empirical relationships. In this paper, we present enhancements to the model of Chang et al. by combining the model of Youd et al., as Chang-Youd models, to make it more convenient and also to extend its usage to be suitable for determining the maximum void ratio. The Chang-Youd models are verified with experimental tests performed by the authors. Compared with the experimental results in the literature, the Chang-Youd models are also effective but more convenient and practical.

\section{Introduction}

The engineering properties of granular soils such as the density, strength, and permeability coefficient are directly affected by the grain size distribution and the shape of the grains, as well as the void ratio. The difference between the maximum and minimum void ratios is the indicator of the relative density of the soil which can be considered as the most important factor that reflects the strength state of the soil [1].

Mono-sized, binary-sized, multisized particles were investigated experimentally by An et al. [2], Fuggle et al. [3], McGeary [4], and Yu and Standish [5]. Also, there are some idealized models of single and two-sized spherical particles to determine the minimum and maximum void ratios [6], but those models do not represent the actual uniformity coefficient or angularity. Hence, some studies proposed empirical relationships to determine the void ratio such as [7] and [8]. Other studies investigated the minimum and maximum void ratio and correlated them with the soil properties such as the particles' diameter corresponding to
50 finer percent, $D_{50}$, and the soil angularity $[9,10]$. There are also analytical models to determine the void ratio of granular soils, such as the ideal model suggested by Kezdi [11] which was found to overestimate the void ratio. A more accurate model was proposed by Aberg [12] and Chang et al. [13]. Recently, Chang et al. [14] presented an analytical model to determine the minimum void ratio, $e_{i}^{M}$, of granular soils composed of $n$-sized particles $\left(d_{1}, d_{2}, \ldots d_{n}\right)$ and their volume fractions $\left(y_{1}, y_{2}, \ldots y_{n}\right)$. They assumed that the minimum void ratio for packings containing particles of equal size of $d_{1}$ is $e_{1}$, and the void ratio of packings containing particle size $d_{2}$ only is $e_{2}$. In the same way, the void ratio for packings containing mono-sized particles $\left(d_{3}, d_{4}\right.$, $\left.d_{5}, \ldots d_{n}\right)$ are $e_{i}$ (i.e., $e_{3}, e_{4}, e_{5}, \ldots e_{n}$ ), respectively. The latter set of values will be used in estimation of the minimum void ratio of the whole mixture by taking a packing containing particles of single size $d_{i}$ (dominant particle size) and considering this diameter as the base packing. The multisize particle packing is built up by adding the larger and the smaller particles to this base packing. The particles smaller than $d_{i}$ will cause an increment in the solid volume and some 
decrement in the volume of the voids combined with some value of increment in the voids' volume due to disturbance. Adding particles with sizes larger than $d_{i}$ will cause increments in both the solid volume and the voids volume. Combining all of these factors together in a mathematical form, we get

$$
e_{i}^{M}=\sum_{j=1}^{n} e_{j} y_{j}-\sum_{j=1}^{i-1} b_{i j} e_{j} y_{j}-\sum_{j=i+1}^{n} a i j\left(1+e_{j}\right) y_{j},
$$

where $y_{j}$ is the finer percent corresponding to particle diameter $d_{i}$, which can be calculated from the gradation curve, $a_{i j}$ is the filling coefficient, $b_{i j}$ is the embedment coefficient, $a_{i j}=f(d, p), b_{i j}=f(d, s)$, and $p$ and $s$ are parameters determined from experimental tests. Chang et al. [14], using a power function to fit the experimental results, proposed the empirical relationship, equation (2), to determine the value of $e_{i}$ :

$$
e_{i}=\alpha d_{i}^{\beta}
$$

where $\alpha$ and $\beta$ are two coefficients based on the fit curve of the experimental results. In Chang et al.'s [14] model, there are four parameters $(p, s, \alpha$, and $\beta$ ) that should be determined, and hence, they required a large number of experimental tests, which makes that the model is not "readily useful in engineering practice for predicting minimum void ratio," as stated by Chang et al. [14].

In this paper, by combining the model of Chang et al. [14] and Youd [8], we proposed the Chang-Youd models to determine the minimum void ratios, which make the experimental tests required to determine the model parameters more convenient and practical. Also, we extended the applicability of equation (1) to be suitable for determining the maximum void ratio.

\section{Enhanced Models to Determine the Minimum and Maximum Void Ratios}

2.1. Enhanced Method to Calculate the Minimum Void Ratio. Four empirical parameters are required for the Chang et al. [14] method, namely, $s, p, \alpha$, and $\beta$. Obtaining these parameters required tedious and time-consuming experimental tests, and for this reason, Chang et al. [14] stated that "Because of the number of experiments required for calibrating the model parameters, this model is not expected to be readily useful in engineering practice for predicting minimum void ratio."

The maximum and minimum void ratios depend on particle's shape, as $R$ and $C_{u}$ stated by Xiao et al. [15] and Youd [8]. Park and Santamarina [16], based on the study of Youd [8], proposed that the minimum void ratio $e_{i}$ can be calculated using empirical formulas, equation (3), without loss of the model accuracy:

$$
e_{i}=-0.012+\frac{0.082}{R}+\frac{0.371}{C_{u}},
$$

where $C_{u}$ is the coefficient of uniformity of the soil, as $d_{60} /$ $d_{10}$, and $R$ is the roundness of the particles $(R=0.14,0.21$,
$0.30,0.41,0.59$, and 0.84 for very angular, angular, subangular, subrounded, rounded, and well-rounded particles, respectively). Using equation (3) here instead of equation (2) has many advantages. Firstly, the minimum void ratio can be obtained by the uniformity coefficient of the soil and roundness of the particles. Secondly, it can be assigned different values of particle roundness for each particle diameter $d_{i}$; because for some granular mixtures, the roundness of the fine-grained particles is different from those of the larger ones, such as the soil tested by Xiao et al. [17] where the particles larger than $10 \mathrm{~mm}$ are rounded to subrounded $(R=0.41 \sim 0.59)$ and the smaller particles are angular to subangular $(R=0.21 \sim 0.30)$. Such a case of different roundness values can be easily taken into consideration in equation (3), while equation (2) gives average values of $\alpha$ and $\beta$ for all the soil particles.

2.2. New Method to Calculate the Maximum Void Ratio. Following the same way of deriving equation (1), we found that it is also possible to determine the maximum void ratio from the model of Chang et al. [14] if we calculate the "maximum" void ratio for a packing containing monosized particles $e_{i}$ (i.e., $e_{1}, e_{2}, \ldots e_{n}$ ), and this can be done by using equation (4) stated by Youd [8] to determine the maximum void ratio into equation (1):

$$
e_{i}=0.032+\frac{0.154}{R}+\frac{0.522}{C_{u}}
$$

2.3. Flow Diagram of Chang-Youd Models. Combining Chang et al.'s [14] and Youd's [8] statements, we proposed Chang-Youd models, given in Figure 1. The soil gradation curve can be divided into $n$ divisions. Particle size $d_{i}(i=1$ to $n)$ is the average particle size for each division, which corresponds to a size ratio $d_{i} / d_{i+1}<1.8$, stated by Chang et al. [14].

\section{Verification of the Chang-Youd Models}

3.1. Verification of the Enhanced Minimum Void Ratio Model. The data CB-Mix-No. 1 and CB-Mix-No. 2 of Youd [8] and G1-1 and G2-8 of experimental tests are used to describe the calculation process of the Chang-Youd model and Chang model. The gradation curve of CB-Mix-No. 1 (Figure 2) is divided into 2 divisions $(n=2)$ and CB-Mix-No. 2 (Figure 2), G1-1 (Figure 3), and G2-8 (Figure 4) are divided into 4 divisions $(n=4)$, respectively. The two sand mixtures' properties, minimum void ratios, and maximum void ratios were measured by the experiment. Roundness can be inscribed within the grain image [8] and are listed in Table 1. The data G1-1 and G2-8 of experimental tests performed by the authors here using 16 sand-gravel mixtures composed of subrounded grain ranged from 0.1 to $19 \mathrm{~mm}$. Their grain size distribution curves are shown in Figures 3 and 4. Based on the study of Xiao et al. [17], where the particles are larger than $10 \mathrm{~mm}, R=0.41 \sim 0.59$, and the particles are smaller than $10 \mathrm{~mm}, R=0.21 \sim 0.30$, the minimum void ratio and the maximum void ratio of G1-1 and G2-8 were obtained 


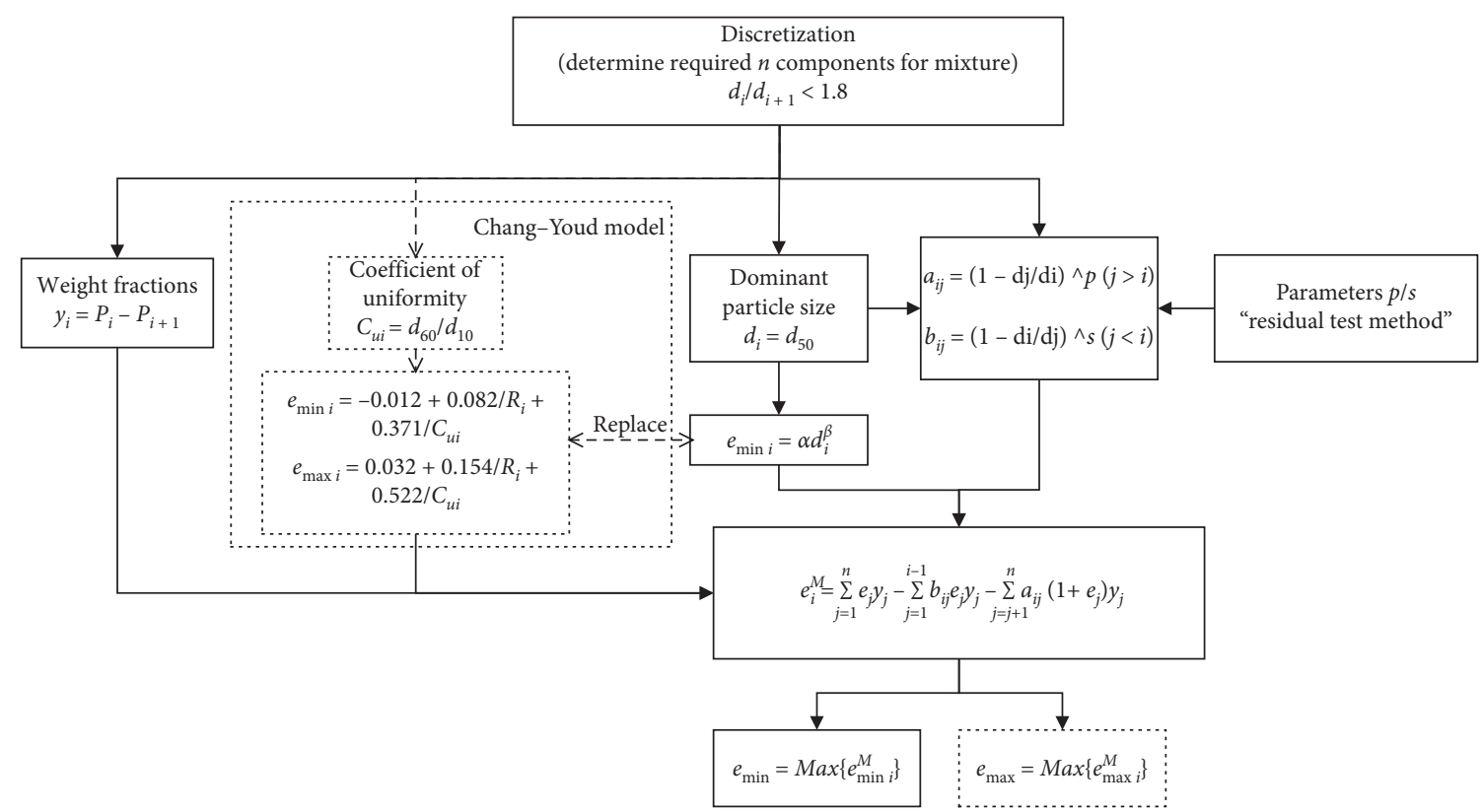

Figure 1: Flow diagram of Chang-Youd Models.

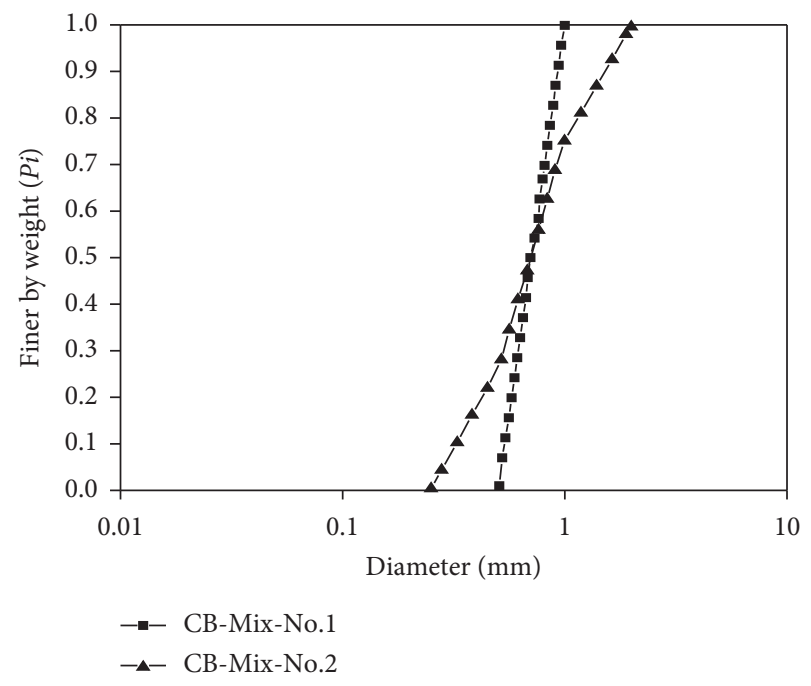

FIgURE 2: Grain size distribution curve of soils 1 and 2 tested by Youd [8].

according to ASTM D4254-16 [18], and the results are shown in Table 1.

The gradation curve of CB-Mix-No. 1 can be reduced to a simple model for binary packing, as CB-Mix-No. 2, G1-1, and G2-8 can be reduced to quaternary packing. Take the binary mixture, for example, let $y_{1}$ and $y_{2}$ be the solid weight fractions for large particle $d_{1}$ and small particle $d_{2}$ and $C_{u i}$ be the coefficient of uniformity for each division, as shown in Table 1.

CB-Mix-No. 1 as binary packing, equation (1) leads to the following expressions:

(i) Large particle $d_{1}$ as dominant particle size:

$$
e_{1}^{M}=e_{1} y_{1}+e_{2} y_{2}-a_{12}\left(1+e_{2}\right) y_{2} .
$$

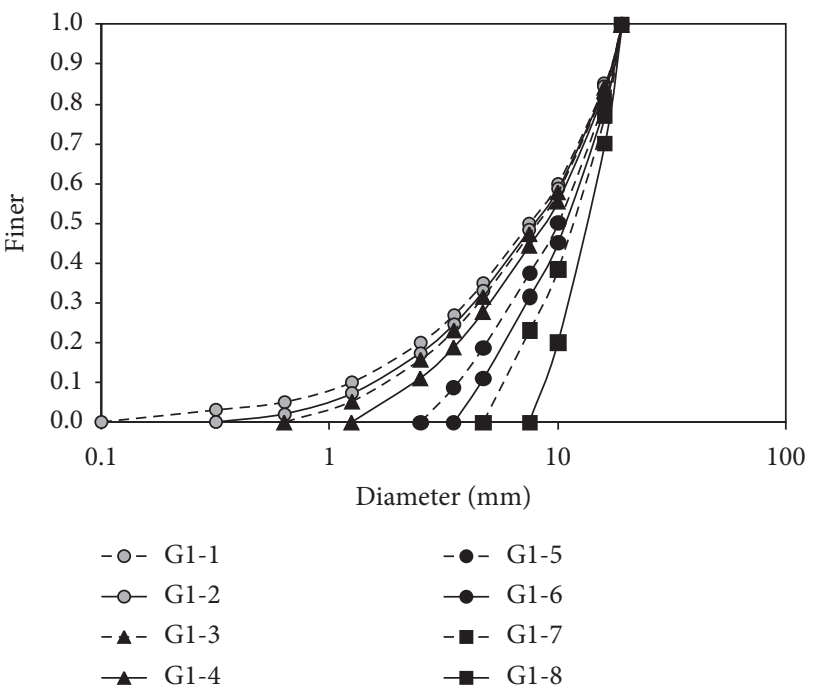

FIGURE 3: Grain size distribution of soils G1-1 to G1-8.

(ii) Small particle $d_{2}$ as dominant particle size:

$$
e_{2}^{M}=e_{1} y_{1}+e_{2} y_{2}-b_{21} e_{1} y_{1}
$$

CB-Mix-No. 2, G1-1, and G2-8 as quaternary packing, equation (1) leads to the following expressions:

(iii) $d_{1}$ as dominant particle size:

$$
\begin{aligned}
e_{1}^{M}= & e_{1} y_{1}+e_{2} y_{2}+e_{3} y_{3}+e_{4} y_{4}-a_{12}\left(1+e_{2}\right) y_{2} \\
& -a_{13}\left(1+e_{3}\right) y_{3}-a_{14}\left(1+e_{4}\right) y_{4} .
\end{aligned}
$$

(iv) $d_{2}$ as dominant particle size: 


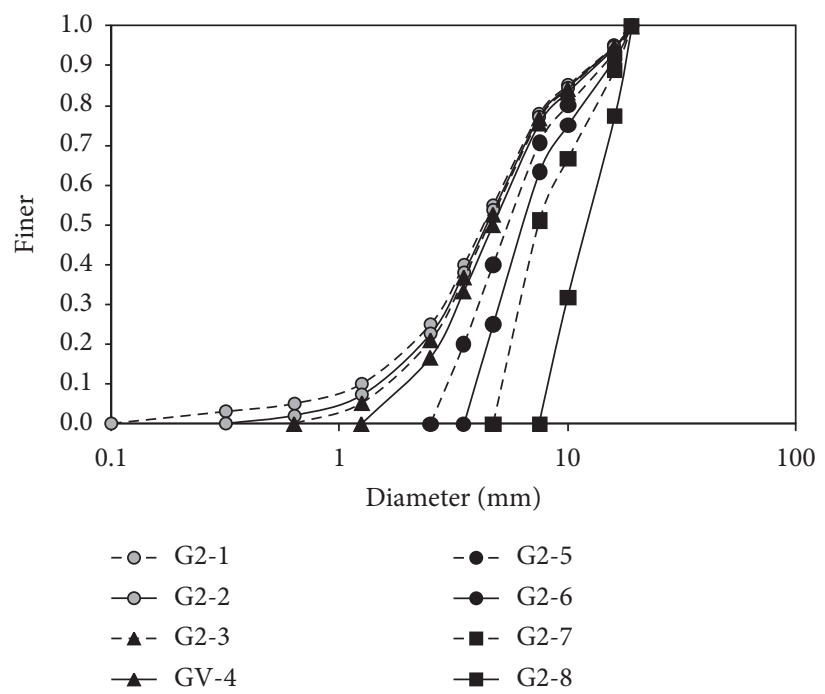

Figure 4: Grain size distribution of soils G2-1 to G2-8.

TABle 1: Properties of sand mixes.

\begin{tabular}{|c|c|c|c|c|c|c|c|c|}
\hline Soil ID & Divisions & $\begin{array}{c}\text { Size range } \\
\mathrm{mm}\end{array}$ & $\begin{array}{l}\text { Weight fractions } \\
\qquad y_{i}\end{array}$ & $\begin{array}{c}\text { Roundness } \\
\qquad R_{i}\end{array}$ & $\begin{array}{l}\text { Coefficient of uniformity } \\
\qquad C_{u i}=d_{60} / d_{10}\end{array}$ & $\begin{array}{c}\text { Dominant } \\
d_{i}=d_{50} \\
\mathrm{~mm}\end{array}$ & $e_{\min }$ & $e_{\max }$ \\
\hline \multirow{2}{*}{ CB-Mix-No. 1} & 1 & $0.70-1.00$ & 0.500 & 0.19 & 1.168 & 0.838 & \multirow{2}{*}{0.705} & \multirow{2}{*}{1.257} \\
\hline & 2 & $0.50-0.70$ & 0.500 & 0.19 & 1.192 & 0.596 & & \\
\hline \multirow{4}{*}{ CB-Mix-No. 2} & 1 & $1.00-2.00$ & 0.250 & 0.19 & 1.432 & 1.411 & \multirow{4}{*}{0.590} & \multirow{4}{*}{1.099} \\
\hline & 2 & $0.70-1.00$ & 0.250 & 0.19 & 1.180 & 0.833 & & \\
\hline & 3 & $0.50-0.70$ & 0.250 & 0.19 & 1.186 & 0.588 & & \\
\hline & 4 & $0.25-0.50$ & 0.250 & 0.19 & 1.380 & 0.348 & & \\
\hline \multirow{4}{*}{ G1-1 } & 1 & $15.72-18.92$ & 0.149 & 0.59 & 1.100 & 17.317 & \multirow{4}{*}{0.242} & \multirow{4}{*}{0.541} \\
\hline & 2 & 7.49-15.72 & 0.349 & 0.41 & 1.494 & 11.609 & & \\
\hline & 3 & $2.51-7.49$ & 0.303 & 0.30 & 1.829 & 5.004 & & \\
\hline & 4 & $0.10-2.51$ & 0.199 & 0.30 & 4.533 & 1.305 & & \\
\hline \multirow{4}{*}{ G2-8 } & 1 & $16.21-19.21$ & 0.226 & 0.59 & 1.091 & 17.710 & \multirow{4}{*}{0.546} & \multirow{4}{*}{0.774} \\
\hline & 2 & $12.86-16.21$ & 0.218 & 0.59 & 1.127 & 14.538 & & \\
\hline & 3 & $10.05-12.86$ & 0.238 & 0.41 & 1.136 & 11.458 & & \\
\hline & 4 & $7.49-10.05$ & 0.318 & 0.30 & 1.165 & 8.775 & & \\
\hline
\end{tabular}

$$
\begin{aligned}
e_{2}^{M}= & e_{1} y_{1}+e_{2} y_{2}+e_{3} y_{3}+e_{4} y_{4}-b_{21} e_{1} y_{1} \\
& -a_{23}\left(1+e_{3}\right) y_{3}-a_{24}\left(1+e_{4}\right) y_{4} .
\end{aligned}
$$

(v) $d_{3}$ as dominant particle size:

$$
\begin{aligned}
e_{3}^{M}= & e_{1} y_{1}+e_{2} y_{2}+e_{3} y_{3}+e_{4} y_{4}-b_{31} e_{1} y_{1} \\
& -b_{32} e_{2} y_{2}-a_{34}\left(1+e_{4}\right) y_{4} .
\end{aligned}
$$

(vi) $d_{4}$ as dominant particle size:

$$
\begin{aligned}
e_{4}^{M}= & e_{1} y_{1}+e_{2} y_{2}+e_{3} y_{3}+e_{4} y_{4}-b_{41} e_{1} y_{1} \\
& -b_{42} e_{2} y_{2}-b_{43} e_{3} y_{3} .
\end{aligned}
$$

Chang et al. [13] determined the filling coefficient $a_{i j}$ and embedment coefficient $b_{i j}$ from experimental results, which are fitted by a power function of the particle size ratio $\left(d_{j} / d_{i}\right)$ :

$$
\begin{aligned}
& a_{i j}=\left(1-\frac{d_{j}}{d_{i}}\right)^{p}, \quad(j>i), \\
& b_{i j}=\left(1-\frac{d_{i}}{d_{j}}\right)^{s}, \quad(j<i) .
\end{aligned}
$$

The $p$ and $s$ are shape parameters, which can be determined by "the residual test method", and the overall range of $s=2 \sim 6$, and the range of $p=2 \sim 7$, stated by Chang et al. [13]. The optimum values $p=2.6$ and $s=2.45$ has the lowest residual for the data CB-Mix-No. 1 , and $p=3.8$ and $s=1.95$ for CB-Mix-No. 2 of Youd [8], G1-1, and G2-8. The result of filling coefficient $a_{i j}$ and embedment coefficient $b_{i j}$ is listed in Table 2.

Chang model and Chang-Youd model predictions are conducted to obtain the minimum void ratios of CB-Mix-No. 1, CB-Mix-No. 2, G1-1, and G2-8, which are compared with the actual values are listed in Table 3 . In Chang model, the 
TABLE 2: Filling coefficient $\left(a_{i j}\right)$ and embedment coefficient $\left(b_{i j}\right)$.

\begin{tabular}{|c|c|c|c|c|c|c|c|c|c|c|}
\hline Soil ID & Division & $\begin{array}{c}d_{i} \\
\mathrm{~mm}\end{array}$ & $j=2$ & $\begin{array}{c}a_{i j} \\
j=3\end{array}$ & $j=4$ & $j=1$ & $\begin{array}{c}b_{i j} \\
j=2\end{array}$ & $j=3$ & $p$ & $s$ \\
\hline CB-Mix-No. 1 & $\begin{array}{l}i=1 \\
i=2\end{array}$ & $\begin{array}{l}0.838 \\
0.596\end{array}$ & $\begin{array}{c}0.048 \\
-\end{array}$ & - & - & $\begin{array}{c}- \\
0.058\end{array}$ & - & - & 2.60 & 2.45 \\
\hline CB-Mix-No. 2 & $\begin{array}{l}i=1 \\
i=2 \\
i=3 \\
i=4\end{array}$ & $\begin{array}{l}1.411 \\
0.833 \\
0.588 \\
0.348 \\
\end{array}$ & $\begin{array}{c}0.034 \\
- \\
- \\
-\end{array}$ & $\begin{array}{c}0.129 \\
0.010 \\
- \\
-\end{array}$ & $\begin{array}{c}0.341 \\
0.128 \\
0.033 \\
-\end{array}$ & $\begin{array}{c}- \\
0.175 \\
0.350 \\
0.576\end{array}$ & $\begin{array}{c}- \\
- \\
0.092 \\
0.348\end{array}$ & $\begin{array}{c}- \\
- \\
- \\
0.174\end{array}$ & 3.80 & 1.95 \\
\hline G1-1 & $\begin{array}{l}i=1 \\
i=2 \\
i=3 \\
i=4\end{array}$ & $\begin{array}{c}17.317 \\
11.609 \\
5.004 \\
1.305 \\
\end{array}$ & $\begin{array}{c}0.014 \\
- \\
- \\
-\end{array}$ & $\begin{array}{c}0.269 \\
0.114 \\
- \\
-\end{array}$ & $\begin{array}{c}0.740 \\
0.632 \\
0.313 \\
- \\
\end{array}$ & $\begin{array}{c}- \\
0.115 \\
0.514 \\
0.858 \\
\end{array}$ & $\begin{array}{c}- \\
- \\
0.333 \\
0.793 \\
\end{array}$ & $\begin{array}{c}- \\
- \\
- \\
0.555\end{array}$ & 3.80 & 1.95 \\
\hline G2-8 & $\begin{array}{l}i=1 \\
i=2 \\
i=3 \\
i=4\end{array}$ & $\begin{array}{c}17.710 \\
14.538 \\
11.458 \\
8.775\end{array}$ & $\begin{array}{c}0.001 \\
- \\
- \\
-\end{array}$ & $\begin{array}{c}0.018 \\
0.003 \\
- \\
-\end{array}$ & $\begin{array}{c}0.072 \\
0.028 \\
0.004 \\
-\end{array}$ & $\begin{array}{c}-\overline{-} \\
0.035 \\
0.131 \\
0.263\end{array}$ & $\begin{array}{c}- \\
- \\
0.049 \\
0.165\end{array}$ & $\begin{array}{c}- \\
- \\
- \\
0.059\end{array}$ & 3.80 & 1.95 \\
\hline
\end{tabular}

Table 3: Minimum and maximum void ratios for CB-Mix-No. 1 (CB-1), CB-Mix-No. 2 (CB-2), G1-1, and G2-8, obtained from the Chang model and Chang-Youd models' prediction and test.

\begin{tabular}{|c|c|c|c|c|c|c|c|c|c|c|c|c|}
\hline \multirow{2}{*}{$\begin{array}{l}\text { Soil } \\
\text { ID }\end{array}$} & \multirow{2}{*}{$n$} & \multirow[b]{2}{*}{$\begin{array}{l}\text { Chang } \\
\text { model }\end{array}$} & & & \multirow{2}{*}{$\begin{array}{c}\text { Chang } \\
\text { model } e_{\text {min }}\end{array}$} & \multirow{2}{*}{$\begin{array}{l}\text { Chang-Youd } \\
\text { model } e_{\min }\end{array}$} & \multirow{2}{*}{$\begin{array}{l}\text { Test } \\
e_{\min }\end{array}$} & \multicolumn{3}{|c|}{$\begin{array}{c}\text { Chang-Youd } \\
\text { model }\end{array}$} & \multirow{2}{*}{$\begin{array}{l}\text { Test } \\
e_{\max }\end{array}$} \\
\hline & & & $\begin{array}{l}\text { Chang-Youd } \\
\text { model }\end{array}$ & $\begin{array}{l}\text { Chang } \\
\text { model }\end{array}$ & $\begin{array}{l}\text { Chang-Youd } \\
\text { model }\end{array}$ & & & & $e_{i}$ & $e_{i}^{M}$ & $e_{\max }$ & \\
\hline \multirow{2}{*}{ CB-1 } & 1 & 0.707 & 0.737 & 0.701 & 0.692 & \multirow{2}{*}{0.701} & \multirow{2}{*}{0.713} & \multirow{2}{*}{0.705} & 1.289 & 1.230 & \multirow{2}{*}{1.248} & \multirow{2}{*}{1.257} \\
\hline & 2 & 0.716 & 0.731 & 0.675 & 0.713 & & & & 1.280 & 1.248 & & \\
\hline \multirow{4}{*}{ CB-2 } & 1 & 0.692 & 0.679 & 0.495 & 0.494 & \multirow{4}{*}{0.622} & \multirow{4}{*}{0.620} & \multirow{4}{*}{0.59} & 1.207 & 0.967 & \multirow{4}{*}{1.119} & \multirow{4}{*}{1.099} \\
\hline & 2 & 0.707 & 0.734 & 0.622 & 0.620 & & & & 1.285 & 1.119 & & \\
\hline & 3 & 0.717 & 0.732 & 0.621 & 0.618 & & & & 1.283 & 1.095 & & \\
\hline & 4 & 0.732 & 0.688 & 0.519 & 0.515 & & & & 1.221 & 0.907 & & \\
\hline \multirow{4}{*}{ G1-1 } & 1 & 0.832 & 0.464 & 0.139 & 0.106 & \multirow{4}{*}{0.214} & \multirow{4}{*}{0.260} & \multirow{4}{*}{0.242} & 0.768 & 0.359 & \multirow{4}{*}{0.511} & \multirow{4}{*}{0.541} \\
\hline & 2 & 0.558 & 0.436 & 0.213 & 0.203 & & & & 0.757 & 0.476 & & \\
\hline & 3 & 0.241 & 0.464 & 0.209 & 0.260 & & & & 0.831 & 0.511 & & \\
\hline & 4 & 0.063 & 0.343 & 0.103 & 0.172 & & & & 0.660 & 0.315 & & \\
\hline \multirow{4}{*}{ G2-8 } & 1 & 0.781 & 0.467 & 0.616 & 0.469 & \multirow{4}{*}{0.636} & \multirow{4}{*}{0.494} & \multirow{4}{*}{0.546} & 0.772 & 0.807 & \multirow{4}{*}{0.836} & \multirow{4}{*}{0.774} \\
\hline & 2 & 0.710 & 0.456 & 0.638 & 0.493 & & & & 0.756 & 0.836 & & \\
\hline & 3 & 0.632 & 0.515 & 0.626 & 0.491 & & & & 0.867 & 0.828 & & \\
\hline & 4 & 0.555 & 0.580 & 0.578 & 0.460 & & & & 0.994 & 0.776 & & \\
\hline
\end{tabular}

coefficients $\alpha=0.7016$ and $\beta=-0.04$ of equation (2) for CBMix-No. 1 and CB-Mix-No. 2, which is stated from Chang et al. [14]. In the Chang model, using equation (2) to fit the G11 G1-8 and G2-1 G2-8 experimental data, and the fit curve is shown in Figure 5. According to the fit curve coefficients, $\alpha=0.0483$ and $\beta=0.9981$ for G1-1, and $\alpha=0.1939$ and $\beta=0.4852$ for $\mathrm{G} 2-8$.

Through the discrepancy between predicted and measured minimum void ratios in Table 3 , both models can well predict the minimum void ratio.

The Chang-Youd model of the minimum void ratio was verified with a data set of 45 soil samples obtained from the literature; 8 samples were obtained from Youd [8], (same samples were also employed by Chang et al. [14]), 6 samples were obtained from Indraratna et. al [19], 31 samples were obtained from Fragaszy and Sneider
[20], and 16 samples from the experimental tests performed by the authors here using 16 sand-gravel mixtures composed of subrounded grain that ranged from 0.1 to $19 \mathrm{~mm}$, and their grains' size distribution curves are shown in Figures 3 and 4. Same samples are calculated by the Chang model too. The data sets involve different grain sizes ranging from silt to gravel; they also involve different particle shapes ranging from angular to rounded particles. The soil properties, as well as the grain size distribution curves, are shown in Figures 2-4 and 6 and Table 4.

Equation (3), suggested here, as well as the other model relations are included in a computer program written by the authors to compute the minimum void ratio. The results of the predicted and the actual minimum void ratios are shown in Figure 7, which are located very close to the equality line. 


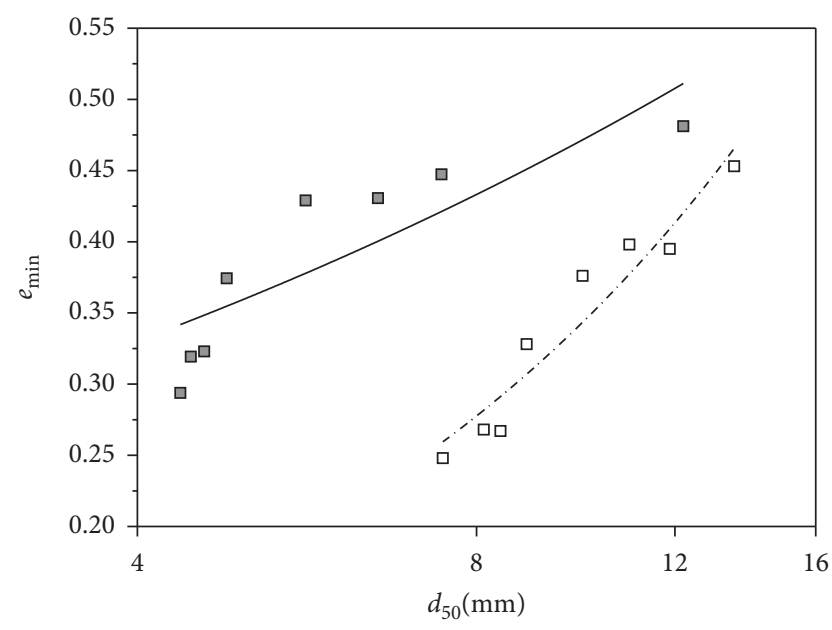

$$
\begin{array}{ll}
\text { ㅁ G2-1 } \sim \mathrm{G} 2-8 & -\mathrm{e}_{\min }=0.1939^{*} \mathrm{~d}_{50} \wedge 0.4852 \\
\text { } \mathrm{G} 1-1 \sim \mathrm{G} 1-8 & -\cdot-\mathrm{e}_{\min }=0.0483 * \mathrm{~d}_{50} \wedge 0.9981
\end{array}
$$

FIgURe 5: Experimental data G1-1 G1-8 and G2-1 G2-8 fitted by equation (2).

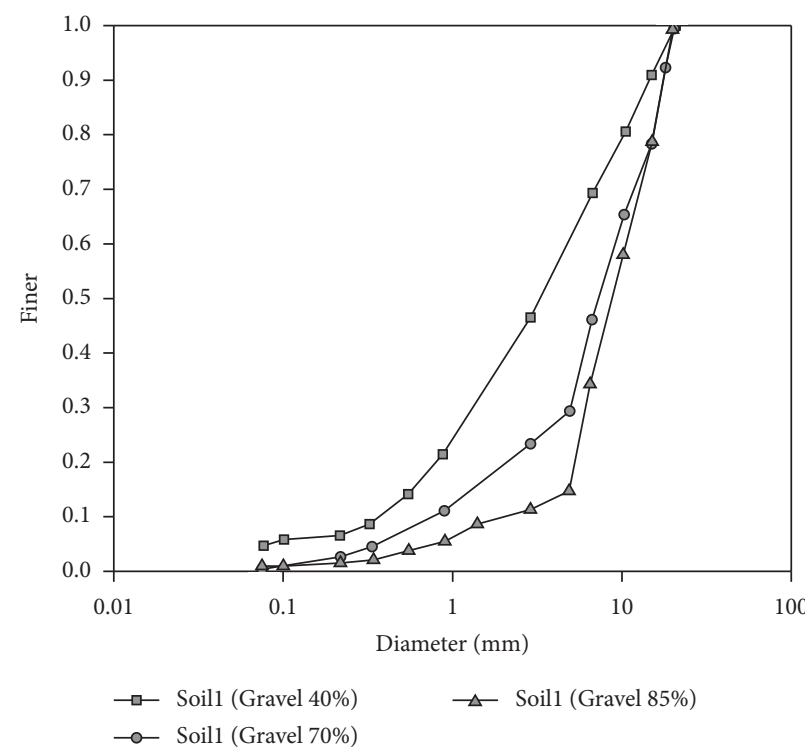

(a)

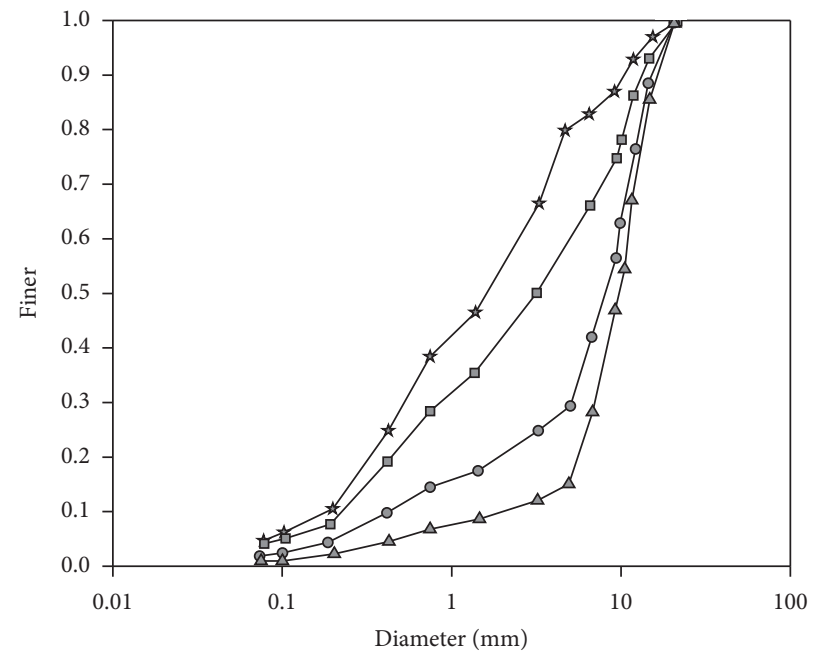

$\rightarrow$ Soil3 (Gravel 20\%) $\quad \longrightarrow$ Soil3 (Gravel 70\%)

(c)

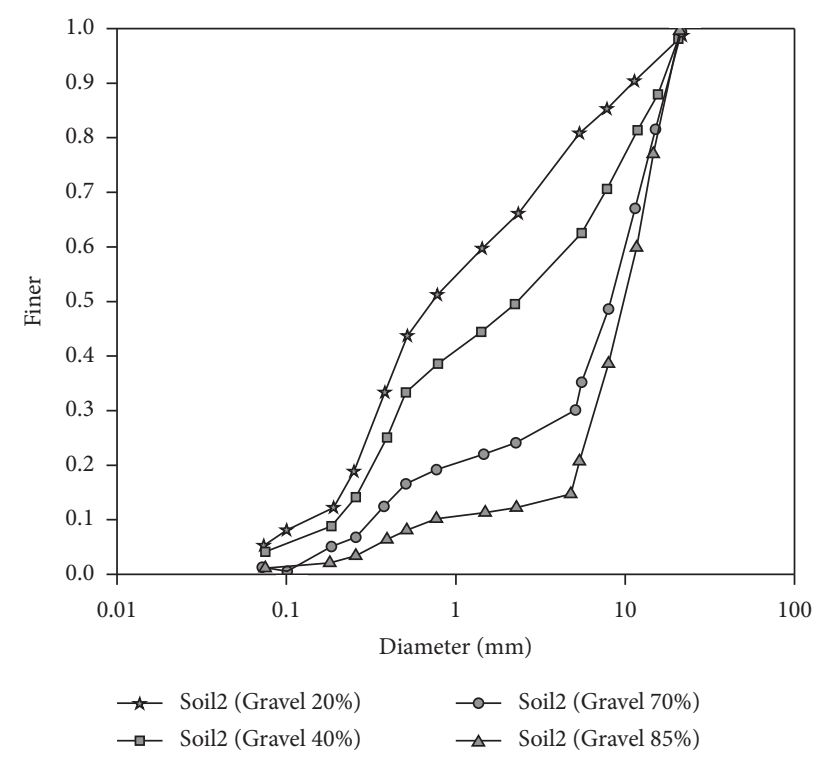

(b)

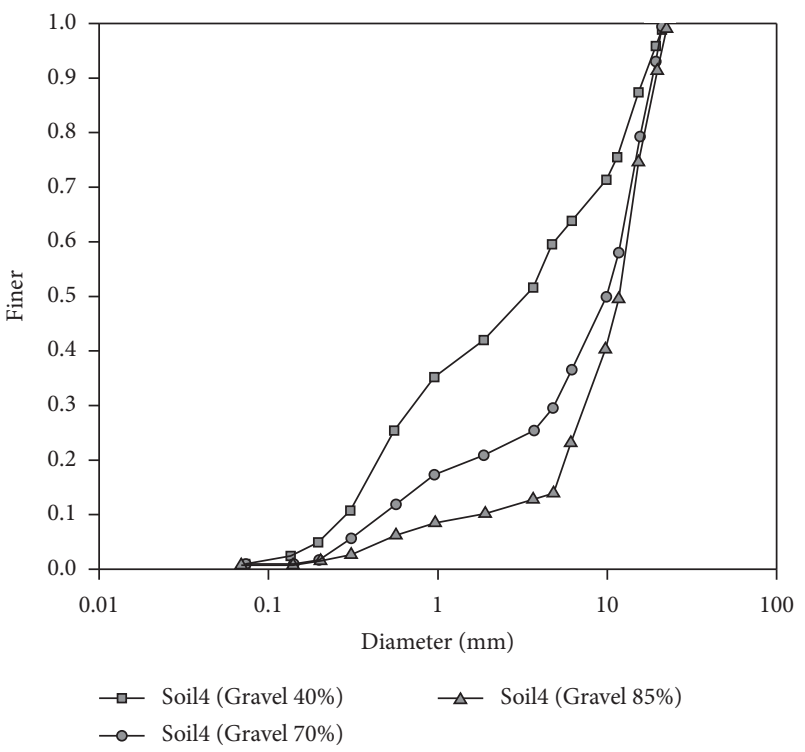

(d)

Figure 6: Continued. 


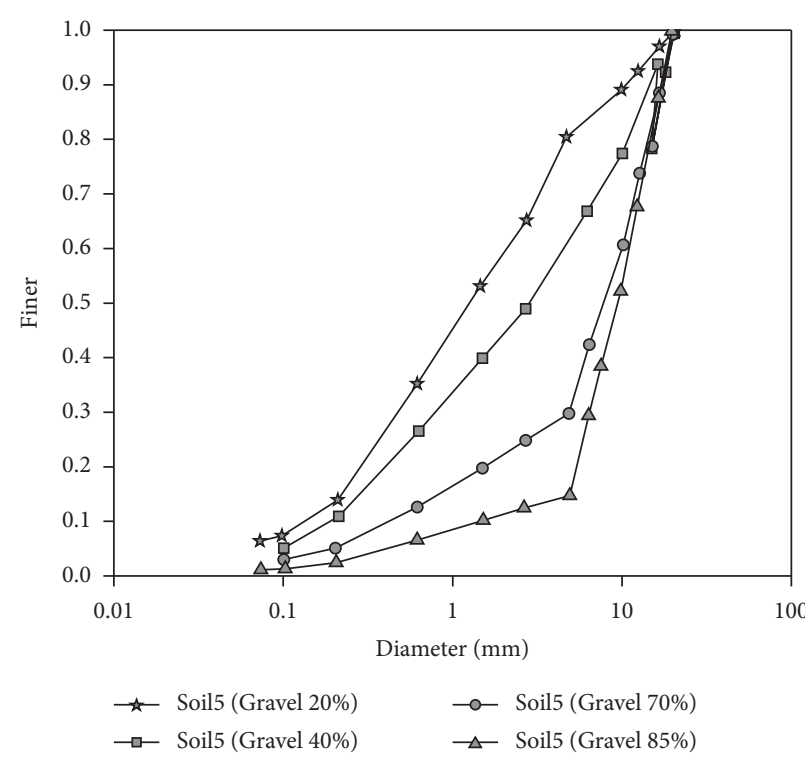

(e)

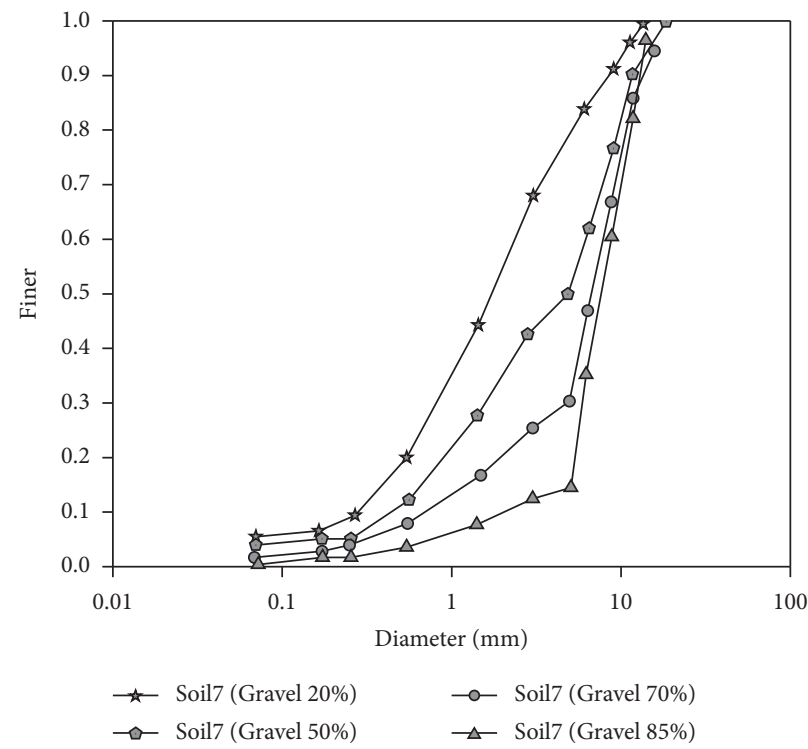

(g)

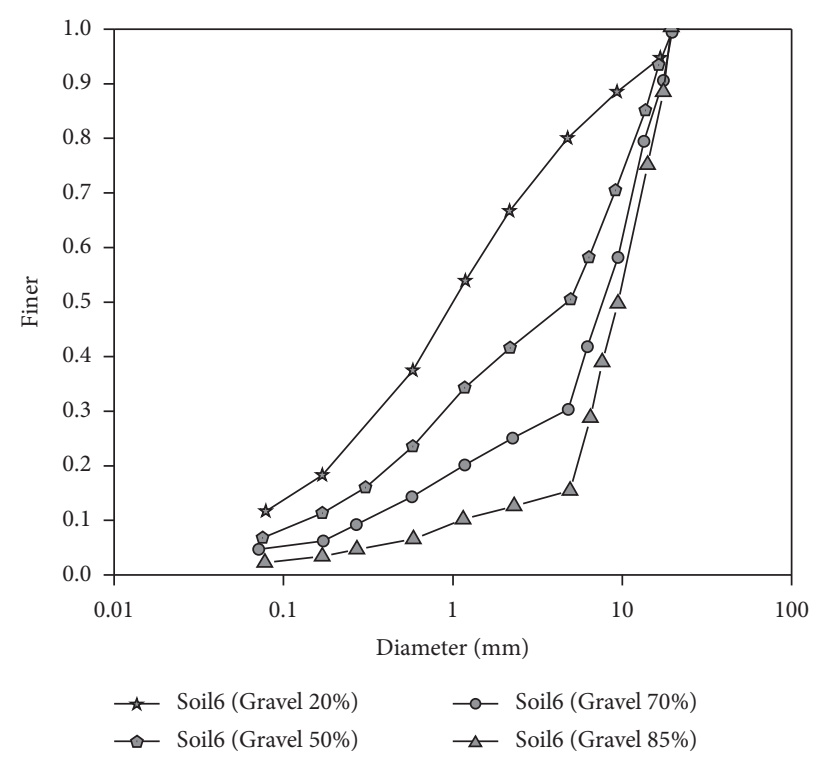

(f)

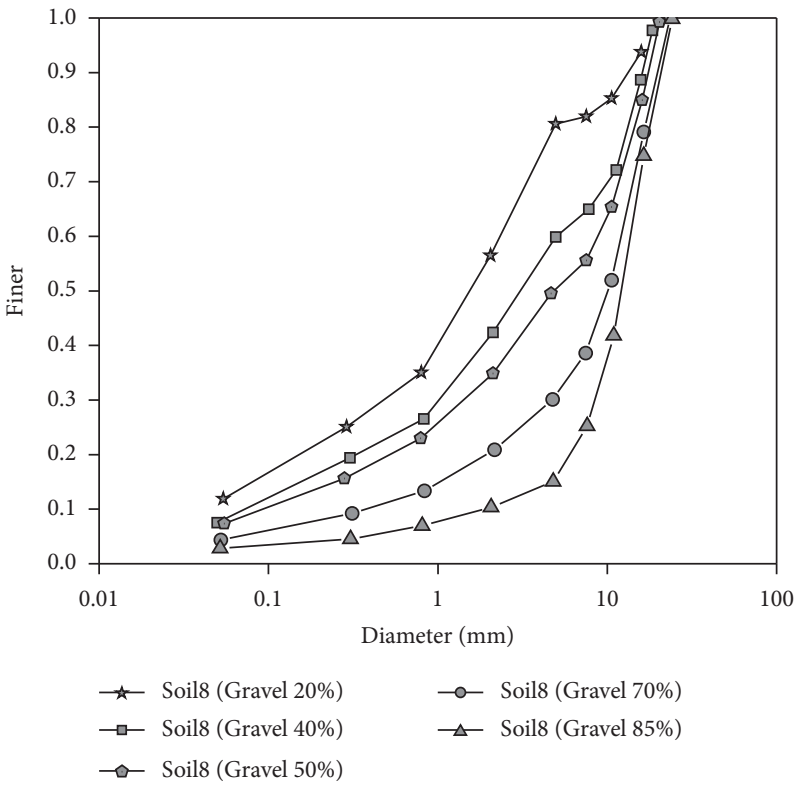

(h)

Figure 6: Grain size distribution curves of soils tested by Fragaszy and Sneider [20]. (a) Soil 1. (b) Soil 2. (c) Soil 3. (d) Soil 4. (e) Soil 5. (f) Soil 6. (g) Soil 7. (h) Soil 8.

Accordingly, we recommend using equation (3) as another alternative to equation (2) to make the model more useful in the engineering practice.

3.2. Verification of the Maximum Void Ratio Model. The fitted curve of filling coefficient $\left(a_{i j}\right)$ and embedment coefficient $\left(b_{i j}\right)$ for the maximum void ratio has the similar trend with that for minimum void ratios [21]. Using the Chang-Youd model, equation (4) replaced equation (2) to obtain the maximum void ratio for CB-Mix-No. 1, CB-Mix-No. 2, G1-1, and G2-8 and are listed in Table 3. The discrepancy between the predicted and tested maximum void ratio is less than $8 \%$, as shown in Table 3 .

The newly suggested model to calculate the maximum void ratio of granular soils was verified with 30 experimental tests, and 8 samples were performed by Youd [8], and 6 samples were performed by Indraratna et al. [19], and the model was also verified with experimental tests performed by the authors here using 16 sand-gravel mixtures composed of subrounded grain that ranged from 0.1 to $19 \mathrm{~mm}$, and 
TABle 4: Soil properties of the soil samples.

\begin{tabular}{|c|c|c|c|c|}
\hline No. & Reference & Soil ID & $e_{\min }$ & $e_{\max }$ \\
\hline 1 & \multirow{6}{*}{ Indraratna et al. [19] } & G1 & 0.615 & 0.825 \\
\hline 2 & & G2 & 0.567 & 0.785 \\
\hline 3 & & G3 & 0.535 & 0.775 \\
\hline 4 & & G4 & 0.484 & 0.747 \\
\hline 5 & & G5 & 0.471 & 0.743 \\
\hline 6 & & G6 & 0.465 & 0.730 \\
\hline 7 & \multirow{8}{*}{ Youd [8] } & MOL-Mix-No. 1 & 0.458 & 0.799 \\
\hline 8 & & MOL-Mix-No. 2 & 0.370 & 0.688 \\
\hline 9 & & MOL-Mix-No. 3 & 0.300 & 0.577 \\
\hline 10 & & MOL-Mix-No. 4 & 0.271 & 0.491 \\
\hline 11 & & CB-Mix-No. 1 & 0.705 & 1.257 \\
\hline 12 & & CB-Mix-No. 2 & 0.590 & 1.099 \\
\hline 13 & & CB-Mix-No. 3 & 0.480 & 0.993 \\
\hline 14 & & CB-Mix-No. 4 & 0.439 & 0.800 \\
\hline 15 & \multirow{31}{*}{ Fragaszy and Sneider [20] } & Soil $1, G=40 \%$ & 0.315 & - \\
\hline 16 & & Soil $1, G=70 \%$ & 0.351 & - \\
\hline 17 & & Soil $1, G=85 \%$ & 0.453 & - \\
\hline 18 & & Soil 2, $G=20 \%$ & 0.309 & - \\
\hline 19 & & Soil 2, $G=40 \%$ & 0.260 & - \\
\hline 20 & & Soil 2, $G=70 \%$ & 0.220 & - \\
\hline 21 & & Soil 2, $G=85 \%$ & 0.329 & - \\
\hline 22 & & Soil 3, $G=20 \%$ & 0.303 & - \\
\hline 23 & & Soil 3, $G=40 \%$ & 0.275 & - \\
\hline 24 & & Soil 3, $G=70 \%$ & 0.297 & - \\
\hline 25 & & Soil 3, $G=85 \%$ & 0.492 & - \\
\hline 26 & & Soil $4, G=40 \%$ & 0.280 & - \\
\hline 27 & & Soil $4, G=70 \%$ & 0.226 & - \\
\hline 28 & & Soil $4, G=85 \%$ & 0.319 & - \\
\hline 29 & & Soil $5, G=20 \%$ & 0.315 & - \\
\hline 30 & & Soil $5, G=40 \%$ & 0.280 & - \\
\hline 31 & & Soil $5, G=70 \%$ & 0.323 & - \\
\hline 32 & & Soil $5, G=85 \%$ & 0.437 & - \\
\hline 33 & & Soil $6, G=20 \%$ & 0.223 & - \\
\hline 34 & & Soil $6, G=50 \%$ & 0.217 & - \\
\hline 35 & & Soil $6, G=70 \%$ & 0.289 & - \\
\hline 36 & & Soil $6, G=85 \%$ & 0.345 & - \\
\hline 37 & & Soil $7, G=20 \%$ & 0.289 & - \\
\hline 38 & & Soil $7, G=50 \%$ & 0.278 & - \\
\hline 39 & & Soil $7, G=70 \%$ & 0.340 & - \\
\hline 40 & & Soil $7, G=85 \%$ & 0.504 & - \\
\hline 41 & & Soil $8, G=20 \%$ & 0.200 & - \\
\hline 42 & & Soil $8, G=40 \%$ & 0.227 & - \\
\hline 43 & & Soil $8, G=50 \%$ & 0.247 & - \\
\hline 44 & & Soil $8, G=70 \%$ & 0.348 & - \\
\hline 45 & & Soil $8, G=85 \%$ & 0.516 & - \\
\hline 46 & \multirow{16}{*}{ This study } & G1-1 & 0.242 & 0.541 \\
\hline 47 & & G1-2 & 0.254 & 0.568 \\
\hline 48 & & G1-3 & 0.268 & 0.570 \\
\hline 49 & & G1-4 & 0.345 & 0.589 \\
\hline 50 & & G1-5 & 0.376 & 0.630 \\
\hline 51 & & G1-6 & 0.398 & 0.669 \\
\hline 52 & & G1-7 & 0.431 & 0.673 \\
\hline 53 & & G1-8 & 0.483 & 0.738 \\
\hline 54 & & G2-1 & 0.296 & 0.631 \\
\hline 55 & & G2-2 & 0.285 & 0.645 \\
\hline 56 & & $\mathrm{G} 2-3$ & 0.323 & 0.643 \\
\hline 57 & & $\mathrm{G} 2-4$ & 0.357 & 0.666 \\
\hline 58 & & G2-5 & 0.401 & 0.672 \\
\hline 59 & & $\mathrm{G} 2-6$ & 0.437 & 0.699 \\
\hline 60 & & $\mathrm{G} 2-7$ & 0.488 & 0.726 \\
\hline 61 & & $\mathrm{G} 2-8$ & 0.546 & 0.774 \\
\hline
\end{tabular}




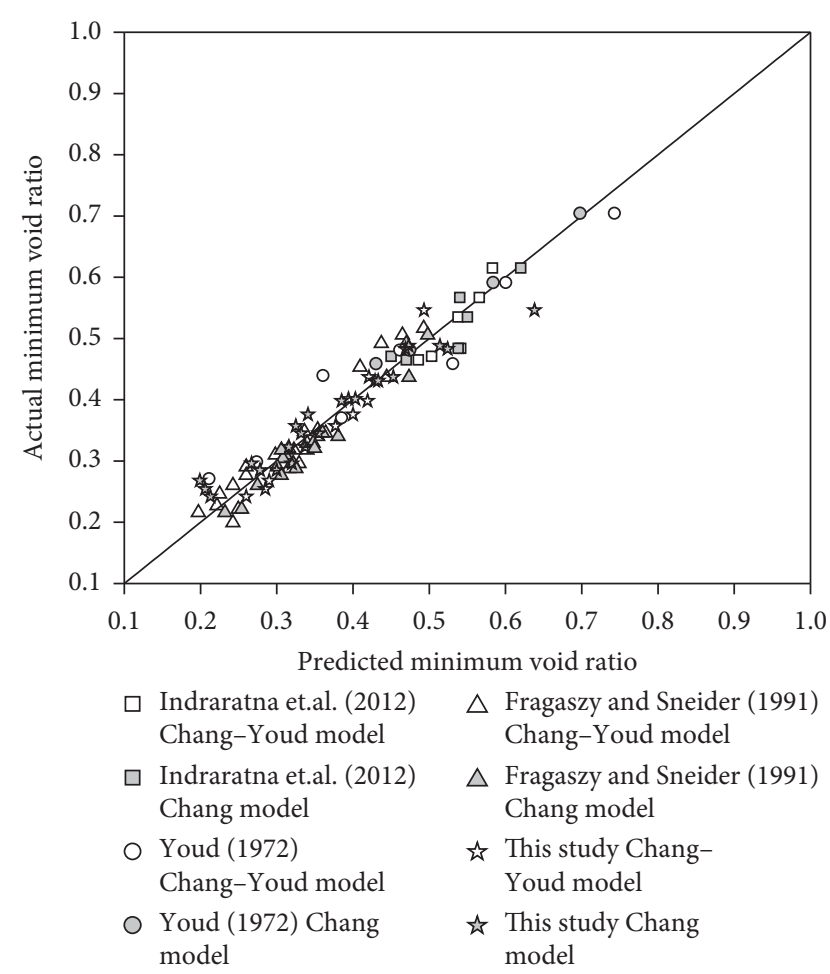

Figure 7: Actual and predicted values of the minimum void ratio.

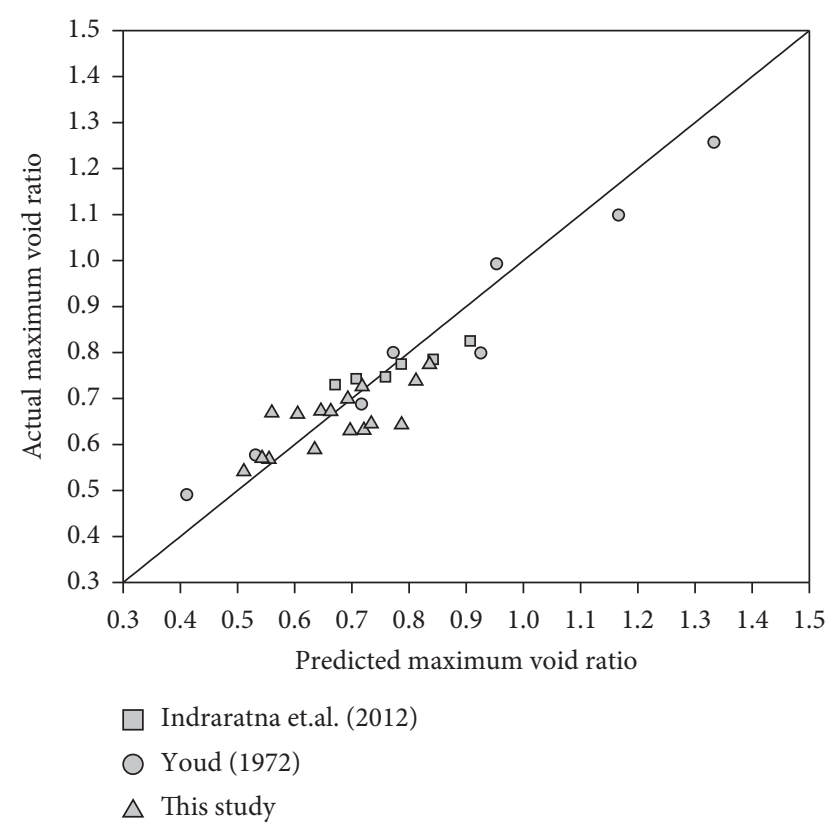

FIGURE 8: The actual and the predicted values of the maximum void ratio.

their grains' size distribution curves are shown in Figures 3 and 4 . The maximum void ratios of these mixtures were obtained according to ASTM D4254-16 [18], and the results are shown in Table 4.
The values of other samples' maximum void ratios were computed. The results of the predicted and the actual void ratios are shown in Figure 8, and as can be shown, there is a very good agreement between the predicted and the actual values, and all the data points are located around the equality line.

The results of a large body of experimental tests (altogether 91 samples) confirm that Chang-Youd models presented here can be used to determine the maximum as well as the minimum void ratio. Also, it requires fewer experimental tests to determine the model parameters.

\section{Summary and Conclusion}

There are many methods to determine the maximum and minimum void ratios of the granular soils, including empirical and analytical methods. Recently, Chang et al. [14] presented an analytical model to determine the minimum void ratio of the granular soils. Although that Chang et al.'s [14] model gives a good agreement between the predicted and the actual values of the minimum void ratios, it requires many experimental tests to determine the values of the four model parameters, namely, $p, s, \alpha$, and $\beta$ which make the model to be not readily usable in the engineering practice. In this paper, we enhanced the Chang et al. [14] model by combining Chang et al.'s [14] and Youd's [8] model, presented as the Chang-Youd model. The minimum void ratio can be obtained by the uniformity coefficient of the soil and roundness of the particles using the Chang-Youd model, which makes the experimental tests required to determine the model parameters more convenient and practical. Also, it is proposed to extend the Chang-Youd model usability to be suitable for determining not only the minimum void ratio but also the maximum void ratio, while the Chang et al. [14] model cannot predict the maximum void ratio. A large number of experimental tests performed by the authors here as well as experimental data available in the literatures were used to verify the Chang-Youd models, and the results show that there is a good agreement between the predicted and the estimated values of the void ratios.

\section{Data Availability}

The data used to support the findings of this study are included within the article.

\section{Conflicts of Interest}

The authors declare that they have no conflicts of interest.

\section{Acknowledgments}

This work was supported by the National Natural Science Foundation of China (Grant no. 51609071) and Fundamental Research Funds for the Central Universities (Grant nos. B200202087 and B200204032). In addition, Xin Liu's 
study at UC Irvine was supported by the China Scholarship Council (Grant no. 201 806715014).

\section{References}

[1] M. Cubrinovski and K. Ishihara, "Empirical correlation between SPT N-value and relative density for sandy soils," Soils and Foundations, vol. 39, no. 5, pp. 61-71, 1999.

[2] X. Z. An, C. X. Li, R. Y. Yang, R. P. Zou, and A. B. Yu, "Experimental study of the packing of mono-sized spheres subjected to one-dimensional vibration," Powder Technology, vol. 196, no. 1, pp. 50-55, 2009.

[3] A. R. Fuggle, M. M. Roozbahani, and J. D. Frost, Size Effects on the Void Ratio of Loosely Packed Binary Particle Mixtures," Geo-Congress 2014 Technical Papers, pp. 129-138, ASCE, Reston, VA, USA, 2014.

[4] R. K. McGeary, "Mechanical packing of spherical particles," Journal of the American Ceramic Society, vol. 44, no. 10, pp. 513-522, 1961.

[5] A. B. Yu and N. Standish, "Porosity calculations of multicomponent mixtures of spherical particles," Powder Technology, vol. 52, no. 3, pp. 233-241, 1987.

[6] P. V. Lade, C. D. Liggio Jr., and J. A. Yamamuro, "Effects of non-plastic fines on minimum and maximum void ratios of sand," Geotechnical Testing Journal, vol. 21, no. 4, pp. 336-347, 1998.

[7] H. W. Humphres, "A Method for Controlling Compaction of Granular Materials," Bulletin No. 159, Highway Research Board, Washington, D.C., USA, 1957.

[8] T. L. Youd, "Factors controlling maximum and minimum densities of sands," in Evaluation of Relative Density and its Role in Geotechnical Projects Involving Cohesionless Soils, E. Selig and R. Ladd, Eds., ASTM, West Conshohocken, PA, USA, pp. 98-112, 1972.

[9] K. Miura, K. Maeda, M. Furukawa, and S. Toki, "Physical characteristics of sands with different primary properties," Soils and Foundations, vol. 37, no. 3, pp. 53-64, 1997.

[10] M. Cubrinovski and K. Ishihara, "Maximum and minimum void ratio characteristics of sands," Soils and Foundations, vol. 42, no. 6, pp. 65-78, 2002.

[11] A. Kezdi, Soil Physics: Selected Topics, p. 160, Elsevier Scientific Co, Amsterdam, The Netherlands, 1979.

[12] B. Åberg, "Void ratio of noncohesive soils and similar materials," Journal of Geotechnical Engineering, vol. 118, no. 9, pp. 1315-1334, 1992.

[13] C. S. Chang, J.-Y. Wang, and L. Ge, "Modeling of minimum void ratio for sand-silt mixtures," Engineering Geology, vol. 196, pp. 293-304, 2015.

[14] C. S. Chang, Y. Deng, and Z. Yang, "Modeling of minimum void ratio for granular soil with effect of particle size distribution," Journal of Engineering Mechanics, vol. 143, no. 9, 2017.

[15] Y. Xiao, G. Ma, B. Nan, and J. S. McCartney, "Thermal conductivity of granular soil mixtures with contrasting particle shapes," Journal of Geotechnical and Geoenvironmental Engineering, vol. 146, no. 5, 2020.

[16] J. Park and J. C. Santamarina, "Revised soil classification system for coarse-fine mixtures," Journal of Geotechnical and Geoenvironmental Engineering, vol. 143, no. 8, 2017.

[17] Y. Xiao, H. Liu, Y. Chen, and J. Jiang, "Strength and deformation of rockfill material based on large-scale triaxial compression tests I: influences of density and pressure," Journal of Geotechnical and Geoenvironmental Engineering, vol. 140, no. 12, 2014.
[18] ASTM, Standard Test Methods for Minimum Index Density and Unit Weight of Soils and Calculation of Relative Density," ASTM D4254-16(2016), ASTM International, West Conshohocken, PA, USA, 2016.

[19] B. Indraratna, V. T. Nguyen, and C. Rujikiatkamjorn, "Hydraulic conductivity of saturated granular soils determined using a constriction-based technique," Canadian Geotechnical Journal, vol. 49, no. 5, pp. 607-613, 2012.

[20] R. J. Fragaszy and C. A. Sneider, Compaction Control of Granular Soils," Final Report WARD, Washington State Department of Transportation, Vol. 230.1, Washington, USA, 1991.

[21] W. Ye, Z. Liu, and Y. Cui, "Modeling of the maximum and minimum void ratios for binary-sized granular materials," in Proceedings of the 7th Asia-Pacific Conference on Unsaturated Soils (AP-UNSAT2019), pp. 463-470, Nagoya City, Japan, August 2019. 